\title{
A TEORIA DA DECISÃO E O HOMEM QUE CONFUNDIU A MULHER COM UM CHAPÉU
}

\author{
Angela Araujo da Silveira Espindola ${ }^{1}$
}

\begin{abstract}
RESUMO: A inspiração para este ensaio surge a partir do conto literário de Oliver Sacks - $O$ homem que confundiu a mulher com um chapéu. A proposta é evidenciar interfaces possíveis e necessárias entre Direito e Literatura, sem desatender exigências metodológicas mínimas. O objeto da reflexão é a decisão judicial e a problemática do ativismo judicial. Especificamente, pretende-se explorar, a partir do conto literário, (a) a importância da narrativa para o Direito e (b) os limites da atuação jurisdicional, tudo isso no contexto da Constituição trintagenária. Tudo isso, com vistas a estabelecer um diálogo entre aquele conto e os principais referenciais teóricos que orientam o argumento central.
\end{abstract}

Palavras-chave: direito e literatura; decisão judicial; ativismo judicial; autonomia do direito.

\begin{abstract}
Na maior parte dos casos, as alucinações não são evidência de loucura. Quando emoções extremas estão envolvidas, qualquer um pode alucinar.
\end{abstract}

(Oliver Sacks)

\section{INTRODUÇÃO}

Mulheres não são chapéus. Decisões judiciais não são atos de vontade. Estas advertências inserem-se, em grande medida, na discussão sobre o significado (ou o sentido) do Direito (Castanheira Neves, 2002;

1 Doutora e Mestre em Direito (UNISINOS). Professora Permanente do Programa de PósGraduação em Direito do Centro Universitário FG (UniFG) e Professora Colaboradora do Programa de Pós-Graduação em Direito da Universidade Federal de Santa Maria (UFSM). Membro Fundadora e Vice-Presidente da Rede Brasileira Direito e Literatura (RDL). Guanambi (BA), Brasil. ORCID: http://orcid.org/oooo-0003-4376-63. CV Lattes: http://lattes.cnpq.br/8242346710380248. E-mail: ange.espindola@gmail.com. 
Cover, 2016) ${ }^{2}$. O jurista não deve - nem pode - confundir a lei com o não direito. Esse o motor da reflexão aqui esboçada.

O título deste ensaio parte do conto literário do escritor e neurologista Oliver Sacks³ (1997, p. 22-37). A reflexão move-se no campo da teoria da decisão apropriando-se das contribuições do Direito $e$ Literatura $^{4}$, cimentada no elevado grau de autonomia do Direito no problema da realização jurisdicional do direito e as críticas ao normativismo e funcionalismo sob a perspectiva de Castanheira Neves (2002, 2003, 2013).

Não se ignora que a obra de Oliver Sacks dialoga intencionalmente com psicologia ou a psiquiatria e não com o direito ou com o tema da teoria da decisão. Este, portanto, o grande desafio do Direito e Literatura, nem sempre alcançado.

Por certo também não é desconhecida a tricotomia Direito na Literatura, Direito como Literatura e Direito da Literatura ${ }^{5}$, mas esta não é objeto de análise explícita. Parte-se da premissa, ora assumida, do Direito como Literatura. Para Cárcova (2014, p. IX), compreender o direito como literatura é admitir uma possível articulação interna entre Direito e Literatura, de modo a descortinar notáveis analogias entre o processo de produção discursiva de Direito e Literatura, tomada em sentido amplo.

[...] law as literature (direito como literatura), se ocupa predominantemente de poner en juego categorías desarrolladas en los últimos cien años por la lingüística y

2 Para Castanheira Neves, o Direito se revela, hoje, fortemente problemático, se volveu em um problema radical, ou seja, não se suscita apenas uma interrogação pela determinação e fundamentação do seu ser direito (não se trata de uma interrogação ontológica), mas sobretudo pelo seu fundamento normativo. Para o autor, a problematicidade atual do direito atinge sua subsistência, está em questão não só o seu verdadeiro sentido, mas a possibilidade mesma do seu sentido. (Castanheira Neves, 2002, p. 10). Para Cover, "o universo normativo é mantido unido pela força de compromissos interpretativos - alguns pequenos e privados, outros imensos e públicos. Esses compromissos - que envolvem funcionários públicos e outras pessoas - determinam o que o direito significa e o que o direito deve ser. Se existissem duas ordens jurídicas com os mesmos preceitos jurídicos e padrões de violência pública - idênticos e previsíveis -, elas iriam necessariamente divergir, essencialmente, quanto ao seu significado se, em uma das ordens, os preceitos fossem universalmente venerados, enquanto na outra eles fossem considerados por muitos como fundamentalmente injustos (Cover, 2016, p. 190-191). Nesse sentido, ver também (Espindola, 2015, 2016b).

3 O conto desta mesma obra de Sacks - A mulher desencarnada - foi analisado sob a perspectiva do Direito e Literatura em (Espindola, 2016a).

4 Ver Chueiri (2006); Trindade (2012); Streck e Trindade (2013); Olivo (2013). Para uma compreensão pontual sobre o estudo do "direito e literatura" no Brasil, ver Trindade e Bernsts (2017).

5 Sobre essa tricotomia, ver Schwartz e Macedo (2006); Cárcova, Price e Ruiz (2014). 
la semiótica: la teoría del discurso, la narratividad, la teoría de la recepción y la semiótica del texto. Esas categorías, proyectadas en el área de la hermenéutica jurídica, permiten disolver buena parte de los problemas que los juristas discuten desde hace ya muchas décadas. [...] Por cierto, con diferentes formas de organicidad, lo que sucede en EEUU se repite en Europa y en América Latina (Cárcova; Price; Ruiz, 2014, p. iv).

Neste mesmo sentido, Nussbaum (1997, p. 36-37) afirma que a imaginação literária, que exalta emoções e sentimentos, deve impregnar, mas sem substituir, as regras que determinam o raciocínio jurídico e moral. Também Castanheira Neves (2003), valendo-se de Segre (1989, p. 57-69), quando define narrar como "uma realização linguística mediata que tem por finalidade comunicar a um ou mais interlocutores uma série de acontecimentos, de moda a fazê-los tomar parte no conhecimento deles, alargando assim o seu contexto pragmático", afirma que para tanto pressupõe-se e traduz-se "um certo saber (que não se reduz à ciência, nem mesmo ao conhecimento denotativo-objectivo) no contexto de uma certa experiência comum ou sócio-cultural, de uma certa práxis humana compartilhada, que convoca concretamente um particular modo comunicativo e seja ou não associado a uma pessoal legitimação do narrador” (Castanheira Neves, 2003, p. 370) . Assim, narrar já é um exemplum ou um sentido paradigmático (assim nos mitos e nas parábolas), uma interpretação, por reconstrução, da realidade e da vida (assim na função literária) (Castanheira Neves, 2003, p. 370-371).

Justifica-se não só a escolha do conto, enquanto narrativa, e a sua posição no argumento deste ensaio, mas sinaliza-se para uma concepção do direito que não reduzir-se ao convencionalismo nem ao pragmatismo jurídico, vez que fundamental uma dimensão ético-jurídica, que compreende a comunidade histórico-social e prática como uma comunidade ético-política-jurídica integrada e integrante, de índole não apenas política (Castanheira Neves, 2003, p. 352-353).

A partir destas premissas, a estrutura deste ensaio é bipartida. Iniciase apresentando o conto literário, evidenciando-se a relevância da narrativa $^{6}$ e sua indispensabilidade para a conquista do significado, afinal,

6 Sobre a dupla dimensão da narração no processo e a ambivalente relação que liga o poder da linguagem à linguagem do poder, ver A. Vezpaziani (2015). 
nenhum fato ou fenômeno existe em separado das narrações que o situam e lhes proporcionam significado. Pretende-se assim conduzir à importância da Literatura (e da compreensão do Direito como Literatura) para a autonomia do Direito. Em seguida, na segunda parte, a partir de metáfora do homem que confundiu a mulher com um chapéu e com suporte na hermenêutica filosófica ${ }^{7}$, quer-se trazer o problema da interpretação jurídica e da decisão judicial em tempos pós-positivistas. O tema não é inédito, nem novo, mas relevante e merece ser enfrentado da forma como ora se propõe, sobretudo, neste trintagenário constitucional brasileiro. O debate é absolutamente necessário e incontornável. Ao final, a partir da reconstrução do argumento de que a decisão judicial não é ato de vontade, não é uma livre atribuição de sentido e também não é um dado, um posto, mas antes o resultado de um processo interpretativo, mediado pelas instituições jurídicas, com suporte necessariamente constitucional, dentro de uma estrutura jurídica de pensamento, retoma-se a importância da autonomia do Direito e, claro, da doutrina ${ }^{8}$. Tudo isso, tendo como pano de fundo, a aproximação da juridicidade à literatura, na linha do já referido movimento Direito e Literatura, procurando um especial sentido para a racionalidade jurídica, distanciando-se do sistematismo normativista e dogmático.

\section{MULHERES NÃO SÃO CHAPÉUS, DECISÕES JUDICIAIS NÃO SÃO ATOS DE VONTADE E ISTO NÃO É UM CACHIMBO}

Na obra O homem que confundiu a mulher com um chapéu, de Oliver Sacks ${ }^{9}$, estão reunidos diversos relatos clínicos transformados pelo autor

7 Os aportes teóricos para as reflexões aqui expostas, portanto, datam da segunda metade do século XX, após a virada hermenêutica e as mudanças da filosofia. Foi Gadamer, em Verdade e método, quem adjetivou a hermenêutica com a expressão filosófica, realizando assim uma mudança na compreensão da hermenêutica, bastante diferente daquela apresentada em Heidegger, aproximando-se de uma linha hursserliana. Como diz Stein (2011, p. 24), a hermenêutica gadameriana se baseia no jogo da pergunta e resposta, e por isso, sempre está num acontecer, em que ela não pretende ter a última palavra.

8 Sobre isso há vasta produção científica desde longa data, com destaques para Castanheira Neves (2002, 2013), Streck (2009a, 2009b, 2017, 2018a); Trindade e Morais, (2011); Trindade e Neto (2017).

9 Oliver Sacks (1933-2015), neurologista e cientista britânico, professor de neurologia e psiquiatria na Universidade de Columbia, foi também exímio narrador, transformando relatos clínicos em peças literárias. Oliver Sacks ganhou maior notoriedade após ter um de seus livros, Awakenings (Tempo de despertar), publicado em 1973, adaptado para o cinema em 1990, protagonizado por Robin Williams e Robert De Niro (Mashall, 1990). 
em verdadeiras narrativas literárias. Os pacientes de Sacks, nos contos, estão imersos em um mundo de sonhos e disfunções cerebrais, mas todos com a imaginação preservada de modo a construírem uma identidade moral própria. $\mathrm{O}$ conto que dá nome ao livro ${ }^{10}$ relata uma forma especial de distúrbio neurológico com quadro de agnosia ${ }^{11}$ visual, cujo paciente parecia estar perdido em um mundo de abstrações sem vida: era capaz de falar sobre as coisas, mas não as via face a face. Todo o senso de realidade estava destruído, embora fosse um músico magnífico e um exímio professor de música: preservado em alguns aspectos neurológicos e arruinado em outros. Um caso raro a desafiar os axiomas da neurologia clássica e até da psicologia. Exatamente por isso, o dano parecia ser no hemisfério direito, pois as síndromes deste lado são quase imperceptíveis se comparadas aquelas do lado esquerdo ${ }^{12}$.

Vamos ao conto e, em seguida, a nossa proposta de reflexão sobre o problema da interpretação jurídica à luz do Direito e Literatura.

O narrador-personagem é Sacks, médico neurologista. O protagonista é dr. P., paciente, músico, cantor e professor universitário. A personagem secundária é a esposa do paciente, que o acompanha a consulta médica. Os fatos se desenrolam inicialmente no consultório médico e findam na casa do paciente. Todo o enredo gira em torno do diagnóstico, prognóstico e eventuais possibilidades terapêuticas do paciente pelo médico, com destaca para a raridade (e incompreensibilidade) dos sintomas.

A trama inicia com a descrição de algumas das confusões esquisitas do dr. P. detectadas no cotidiano. Ele parecia reconhecer as pessoas pela voz, mas não pelos rostos. Acessava o mundo pela audição, não pela visão, embora não fosse cego. Tudo indicava que o dr. P. havia perdido a capacidade de reconhecer rostos e passou a vê-los onde eles não existiam. "Ele afagava o topo de hidrantes e parquímetros pensando que eram

10 Esse conto de Oliver Sacks foi discutido no Programa "Direito \& Literatura", veiculado pela TV Justiça, sob o tema "Erro judiciário" e contou com a participação dos professores Adriano de Brito Naves, Angela Espindola, Draiton Gonzaga de Souza (Streck, 2018c). Também foi objeto de análise na coluna "Senso Incomum", do Consultor Jurídico, por Lenio Streck (2018d).

11 As agnosias, na literatura médica, constituem funções cognitivas de reconhecimento, relacionam-se aos processos perceptivos, os quais permitem ao indivíduo reconhecer ou não tudo o que se encontra no meio ambiente. Neste sentido, consultar Doretto (2002).

12 De acordo com Sacks (1997), os danos no hemisfério direito do cérebro relacionam-se com distúrbios neurológicos que afetam a essência do indivíduo e sua sensibilidade emocional e psicológica. 
cabeças de crianças; dirigia-se cordialmente aos puxadores esculpidos dos móveis e se espantava quando eles não respondiam" (Sacks, 1997, p. 22). Imaginando tratar-se de problema de visão, decorrente da diabetes, havia consultado um oftalmologista que o encaminhou a um neurologista.

$\mathrm{Na}$ anamnese neurológica, o narrador-personagem descartou qualquer traço de demência ou problema de oftalmológico, embora identificasse algo estranho, como se o paciente o encarasse com os ouvidos e não com os olhos. Questionado se reconhecia algum problema visual, o paciente respondeu: "Não, não diretamente, mas de vez em quando cometo erros" (Sacks, 1997, p. 23). Foi durante o exame neurológico que a primeira experiência bizarra aconteceu: após o término de um bem-sucedido teste de reflexos no pé, o médico verificou que calçar os sapatos, o paciente confundia o pé com o sapato e o sapato com o pé, vendo um no outro. Dr. P, o paciente, não conseguia ver o todo, apenas detalhes, que localizava como os bips de uma tela de radar. "Não tinha a menor noção de paisagem ou cena" (Sacks, 1997, p. 24). Como se visse o texto, sem contexto; o homem, sem sua historicidade; o direito sem sua normatividade. Como se interpretação e aplicação fossem coisas distintas.

Num outro exame, o médico mostrou-lhe a capa de uma revista e pediu que o paciente descrevesse a imagem. Na descrição, olhando para fora da revista, fabulava características inexistentes, como se a ausência de características na figura real o tivesse levado a imaginar para além da imagem (Sacks, 1997). Descrevia o mundo conforme sua consciência, desconectado da realidade.

Convencido de que havia se saído muito bem nos exames e dando por concluída a consulta, olhou solipsisticamente ao redor procurando seu chapéu, estendeu a mão e agarrou a cabeça da esposa, tentando erguê-la e tirá-la para pôr em sua cabeça, confundindo-a com um chapéu. "Ela olhava como se estivesse acostumada com as coisas assim" (Sacks, 1997, p. 24-25). Dr. Sacks não conseguiu realizar um diagnóstico neurológico ou neuropsicológico. Intrigava-lhe como alguém podia estar preservado em alguns aspectos e tão incompreensível e absolutamente arruinado noutros.

Numa segunda consulta, realizada à domicílio, novos testes foram aplicados. Dr. P. percebia a realidade por vezes pelo olfato e, principalmente, pela audição, mas não pela visão, embora não houvesse 
nada errado com os seus olhos. Ele era capaz de reconhecer uma rosa pelo olfato, teve dificuldade de reconhecer uma luva como uma luva, mesmo olhando e tocando-a. Visualmente, estava perdido em um mundo de abstrações sem vida. Era capaz de falar sobre as coisas, mas não as via face a face. Funcionava exatamente como uma máquina, construía o mundo como um computador o constrói, por meio da características essenciais e relações esquemáticas. E nada disso atrapalhava seu cotidiano, salvo quando percebia o erro, mas normalmente não percebia. "O esquema podia ser identificado [...] sem que a realidade fosse percebida" (Sacks, 1997, p. 29). Todo o senso de realidade estava destruído. Mas ele parecia ter se adaptado àquele déficit interpretativo. Para fazer alguma coisa, precisava transformá-la em uma canção. A música tomara o lugar da imagem ${ }^{13}$ (Sacks, 1997, p. 31).

Para Sacks (1997, p. 33), aquele paciente representava um caso raro, extraordinário. Seria um caso único, não fosse por outro semelhante reportado na literatura médica, em 1956. Sem dúvida um desafio para a neurologia e para a psicologia, pois era um caso em que o paciente perdera por completo o mundo como representação, preservando-o inteiramente como música ou vontade! Não conseguia fazer um julgamento cognitivo, embora fosse fértil na produção de hipóteses cognitivas. Segundo Sacks, o caso do dr. P. teria fascinado Schopenhauer, para quem a música era pura vontade (Schopenhauer, 2001).

O discernimento, afirmava Sacks (1997, p. 34), é a faculdade mais importante que possuímos. No entanto, a derrocada da capacidade de discernir, que constitui a essência de numerosos distúrbios neuropsicológicos, não é objeto de estudo da neuropsicologia (Sacks, 1997, p. 34-35).

O conto nos coloca diante de uma particular incapacidade de interpretar. Duas situações podem ser destacadas para além daquela que dá nome ao conto, ou seja, a confusão entre o chapéu e a cabeça: (a) o homem não conseguia reconhecer uma luva com uma luva, (b) o homem, olhando para a capa de uma revista, descrevia cenas que extrapolavam a realidade.

\footnotetext{
13 No conto, Dr. Sacks não conseguiu chegar a um diagnóstico preciso, mas prescreveu uma vida que consista inteiramente em música, vez que se ela já era o centro da vida do dr. P., logo deveria fazer dela toda a sua vida (Sacks, 1997, p. 32).
} 
Na verdade, o homem, vivendo e comportando-se com um solipsista, não conseguia fazer um julgamento cognitivo da realidade, mas não se importava com isso, salvo quando lhe avisam o erro. Na verdade, não parecia ser o erro em si um incômodo, mas o fato de ele ser advertido sobre o erro.

O conto presta-se como uma metáfora para falarmos sobre o problema decisionismo ${ }^{14}$. Tem razão Ernildo Stein, citado por Streck (2018a, p. 82) "não é a realidade que é contraditória; nossos discursos sobre a realidade é que são contraditórios”. Confunde-se a realidade com a estrutura da realidade e, por isso, não se pode fazer enunciados assertóricos (Streck, 2018b).

O conto caricaturiza em narrativa a importância da linguagem e do linguistic turn. É ai, exatamente ai, que reside a importância da Literatura (Karam, 2017; Karam e Alcântara, 2019), apresentando-se como uma alternativa possível para que o direito aproprie-se das contribuições do giro ontológico-linguístico (linguistic turn), a partir do qual se transfere o próprio conhecimento para a linguagem, pois o sujeito não é o fundamento do conhecimento.

O conto de Sacks poderia ser ilustrado pela imagem revolucionária do surrealista René Magritte, Ceci n'est pas une pipe (1929). A obra é uma reação contra o racionalismo e igualmente demonstra que entre o objeto do pensamento e a representação existe um espaço (de reflexão e de interpretação). A representação do cachimbo não é o cachimbo, assim como

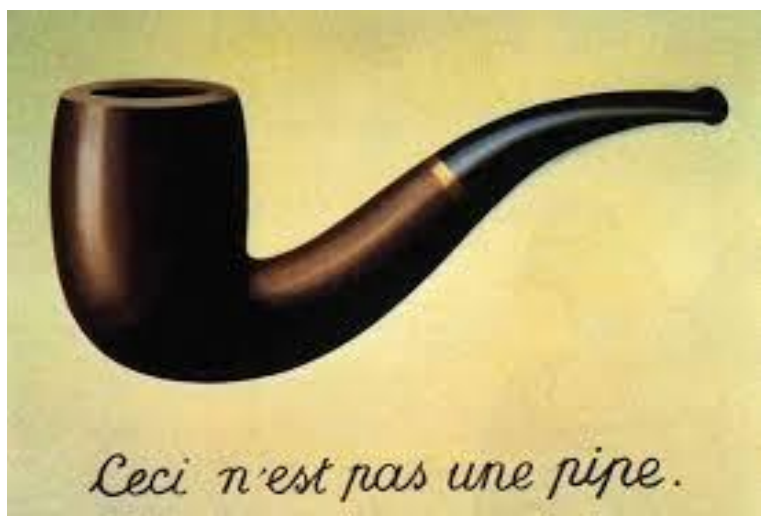
a representação do chapéu não é o chapéu e, por óbvio, a cabeça não é um chapéu, embora um sirva ao outro. $\mathrm{O}$ mapa não é o mundo, nem o mundo está no mapa. As palavras não refletem a essência das coisas; elas se

René Magritte, Isso não é um cachimbo (1929).

14 O problema do decisionismo vem sendo explorado desde longa data, mas sobretudo nas últimas duas décadas. Sobre o tema, consultar Barroso (2009), Cittadino (2001), Streck (2009b), Tassinari (2013), Trindade e Morais (2011), Trindade e Neto (2017), Trindade e Rosenfield (2015). 
prestam para que possamos nos referir às coisas concretas e não para representar a essência. E é por isso também que não se pode atribuir qualquer sentido às palavras e, portanto, às coisas ${ }^{15}$.

O conto de Sacks e a imagem de Magritte, de alguma forma, complementam-se: a partir da primeira, tem-se que não podemos atribuir sentido às coisas, a partir da segunda, tem-se que as palavras não refletem a essência das coisas. No direito, conforme será exposto no item seguinte, temos que as decisões judiciais não são atos de vontade, fazendo-se necessária a superação do positivismo voluntarista. E é por isso que o direito não é aquilo que emana nos tribunais, por si só. Assim como também não é um dado, um pressuposto objetivo a partir do qual se dá a interpretação jurídica (Castanheira Neves, 2003; Dworkin e Rios, 1999). O direito é fruto de contexto intersubjetivo de fundamentação (Streck, 2013), é resultado da mediação judiciativa entre sistema e problema (Castanheira Neves, 2013).

Disto, tem-se que o ativismo decorre de um casuísmo que desconsidera que o problema normativo-concreto do juízo não exige só o sentido normativo-jurídico determinando na norma uma adequação problemático-concreta. Na verdade, o problema normativo-jurídico exige o sentido concreto normativo juridicamente fundado, ou seja, é válido com fundamento na normatividade jurídica fundamentantemente constitutiva da validade jurídica (Castanheira Neves, 2003, p. 346) e, consequentemente, a interpretação normativa é o próprio núcleo da concreta manifestação do direito e o direito, uma prática interpretativa, uma prática normativamente interpretativo-judicativa. Sem essa compreensão, mulheres poderão ser confundidas com chapéus e decisões com ato de vontade e toda representação do charuto será o charuto propriamente dito. Sem esse cuidado, os juristas passarão a confundir o direito com aquilo que eles diziam ser o direito.

\section{MAS AFINAL, O QUE SÃO CHAPÉUS E DECISÕES JUDICIAIS E O QUE É ISTO?}

A interdisciplinariedade que move a aproximação entre Direito e Literatura $^{16}$ é a mesma que redimensiona o século XXI, as concepções de

\footnotetext{
15 Nesse sentido recomenda-se ler Streck (1999, 2012, 2018c).
} 
ciência e de verdade. No Brasil, celebramos recentemente a Constituição Balzaquiana e comemoramos o seu ciclo de saturno. Sobrevivemos ao extremado e breve século XX, suas guerras e suas conquistas e chegamos ao (também) interessantíssimo século XXI, com alguns aprendizados e muito a aprender ${ }^{17}$.

Apesar de a humanidade ter vivido e ultrapassado a Era dos Extremos (Hobsbawm, 1995), constituindo-se hoje o cenário de um Tempo Interessante (Hobsbawm, 2002), o Direito parece não ter se apropriado das contribuições trazidas pelo giro linguístico ou viragem linguística ${ }^{18}$ (Streck, 1999, 2017), ponto alto da filosofia ocidental no século XX e grande alvo de atenções neste século XXI.

É sobretudo a partir de Gadamer (1997, p. 397-410) que passamos a entender que o indivíduo que quer compreender não pode se entregar, desde logo, às opiniões próprias e prévias, ignorando o sentido do texto. Não se trata de afirmar que o intérprete seja neutro ou deva anular-se, mas antes que precisa dar conta das próprias antecipações de sentido e suspender seus prejuízos e preconceitos inautênticos. ${ }^{19}$

16 Sobre o tema ver Henriete Karam (2017).

17 As expressões "breve", "extremado" e "interessante" assumem aqui o sentido dado pelo historiador Eric Hobsbawm para definir o século XX. Um século breve, por que seus principais acontecimentos podem ser condensados no período de 1914 a 1991, em três eras: era das catástrofes, era de ouro e era dos desmoronamentos. Um século marcado por extremos, por que foi o mais extraordinário e o mais terrível da humanidade, com grandes conquistas e grandes perdas (Hobsbawm, 2002).

18 De fato um dos aspectos mais importante do século XX, na filosofia ocidental, foi o linguistic turn, batizado por Gustav Bergmann e, ao mesmo tempo, também Frege e Peirce (Rorty, 1990), quando a linguagem passa a assumir lugar de destaque não só na filosofia, mas nas humanidades. Lamentavelmente, no Direito, segundo Streck e Stein, esse fenômeno não ecoou suficientemente. Para Donald Davidson, a superação da dualidade sujeito-objeto, possível após o giro linguístico, é um caminho sem volta. Cada vez mais a linguagem será alvo de atenções no século XXI e as suas primeiras duas décadas já demostram isso irrefutavelmente.

19 Uma exploração sobre o pensamento gadameriano é vital para identificar as premissas do argumento central deste ensaio. No entanto, não é o objetivo deste ensaio explicitá-lo aqui, mas antes assumi-lo trazendo algumas referências. É importante assumir como premissa, à luz da hermenêutica filosófica, que "compreender é, essencialmente, um processo de história efeitual" (Gadamer, 1997, p. 396) e, portanto, a "consciência da história efeitual é em primeiro lugar consciência da situação hermenêutica” (Gadamer, 1997, p. 399). Para Gadamer (1997, p. 406), "a intepretação não é ato posterior e ocasionalmente complementar à compreensão. Antes, compreender é sempre interpretar, e, por conseguinte, a interpretação é a forma explícita da compreensão. Relacionado com isso está também o fato de que a linguagem e a conceptualidade da intepretação foram reconhecidas como um momento estrutural interno da compreensão; com isso o problema da linguagem que ocupava uma posição ocasional e marginal passa a ocupar o centro da filosofia”. 


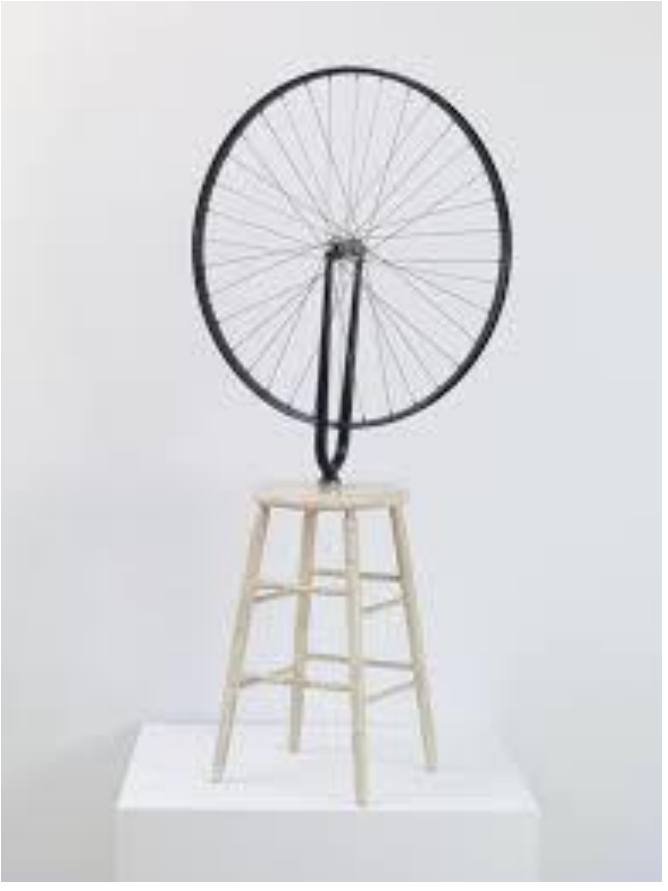

Marcel Duchamp, Roda de bicicleta (1951).

Assim como uma obra de arte não pode ser vista em seu isolamento, desconectada do tempo e lugar em que está inserida, pois há uma rede de compreensão compartilhada entre seu horizonte de sentido e aquele que a observa, um caso ou um texto jurídico também não pode sê-lo. Se compreendermos que o intérprete, possuiu uma précompreensão e participa na construção do sentido do objeto, ao mesmo tempo que esse objeto também modifica a compreensão do intérprete ${ }^{20}$ estamos a um passo de dar conta das antecipações de sentido, aproximando-nos da resposta adequada ao problema do direito (Streck, 2012) e, ao fim e ao cabo, também do problema da intencionalidade do direito (Castanheira Neves, 1998).

Ora, como bem refere Castanheira ${ }^{21}$, desde Bülow e Radbuch se sabe que "a interpretação é o resultado do seu resultado" (1995a, p. 370-371), ou seja, que a interpretação não é uma determinação $a$ priori, seja exegética ou analítica, de uma normatividade em abstrato e em si. A interpretação é constituída pela relação problemático-normativa entre a norma e o caso concreto. Assim, para Castanheira, tem-se que:

20 Está aqui esboçada uma compreensão bastante superficial do que é o complexo conceito do círculo hermenêutico em Gadamer, na hermenêutica filosófica. Recomenda-se aprofundar o conceito em Gadamer (1997) e na produção de Streck (1999, 2017).

21 Castanheira Neves (2013) critica o funcionalismo e o normativismo, apresentando o jurisprudencialismo, que se estrutura a partir da relação (dialética) entre sistema jurídico (princípios, normas, jurisprudência e doutrina) e problema jurídico (o caso), devendo o direito assumir-se como uma tarefa, ou seja, como um constituto-constituendo, vez que não é um dado, um acabado, mas construído a partir de uma (sempre nova) experiência problemática normativa. O sistema jurídico é problematicamente aberto, não intencionalmente autossuficiente e possui uma racionalidade prático-normativa autônoma). Sobre o tema, consultar (Castanheira Neves, 2013). No pensamento jurisprudencialista, todo problema jurídico é único e irrepetível, que coloca uma pergunta que é também única e irrepetível. Nessa perspectiva, não existe distinção, como faz Dworkin, entre casos fáceis e casos difíceis. 
[...] a interpretação apenas se consuma na decisão concreta (no concreto juízo normativamente decisório) e é o conteúdo normativo-jurídico assim determinadoconstituído - num processo dialético análogo ao do "círculo hermenêutico" - que acaba por imputar-se à norma interpretanda, reconstituindo-a e enriquecendo-a nessa mesma medida.

Para Castanheira Neves (1998, p. 2), o próprio apelo e importância dados hoje à jurisdição revela, na jurisdição existente, a falta de jurisdição para que se apela. Daí a importância sobre o problema do sentido, que não só se constitui de problemas internos, mas também de problemas estruturais (externos) ${ }^{22}$. Afinal, qual o papel do juiz, que está entre o legislador e a sociedade, fazendo-lhes a mediação judiciativa? (Castanheira Neves, 1995, p. 9-50).

No conto de Sacks, a forma como o paciente dr. P interpreta o mundo se dá a partir de uma formal distinção metodológica de interpretação e aplicação, considerando-as operações discretas e distintas uma da outra o que culmina na identificação da interpretação com uma determinação $a$ priori, exegética ou analítica. Os sintomas do paciente são uma caricatura deste esquema discriminatório.

Tem razão Castanheira Neves (1995a, p. 374) ao afirmar, com apoio em Stammler e Heck, que "quando se aplica um parágrafo de um código, não só se aplica todo o código, como se faz intervir o pensamento do direito em si mesmo”. Desta forma, cada decisão jurídica concreta pode atuar o conteúdo global da ordem jurídica.

22 Para Castanheira (1998, p. 2-3), a estrutura organiza, sistematiza, permite o funcionamento, "mas só o sentido funda e constitutivamente sustenta". Portanto, uma crise (a crise do juiz e da justiça) só pode ser superada por uma crítica, ou seja, "por uma reflexão refundadora de um novo sentido”. São problemas estruturais, para Castanheira: a) os problemas diretamente político-constitucionais, na forma de problema institucional (de organização, de governo) ou de problema de legitimação decisória; ainda, b) o problema estatutário, relacionado a tudo que diz respeito as normativas e garantias da magistratura, seu controle e responsabilidades específicas; e c) o problema funcional ad hoc, referindo-se ao modo como os consumidores da justiça esperam que os tribunais funcionem, suas as expectativas culturais, políticas e técnicas. Esses problemas estruturais, insiste Castanheira, são problemas externos ao exercício da função jurisdicional, com os quais comumente ocupam-se à mídia e os jornalistas. São problemas que consideram o poder, a organização, a responsabilidade e o modo deste exercício, mas não se referem a intencionalidade material da própria jurisdição como jurisdição e o sentido que ela assume e realiza. Os problemas estruturais são condições de possibilidade da jurisdição que se pretende. No entanto, é só o problema intencional, o problema do sentido, é decisivo, traz em si momento constitutivo da jurisdição, toca a essência não a forma. 
Assumimos aqui, na esteira de Castanheira Neves, como decisivo o problema da intencionalidade do direito, do sentido do direito e, por conseguinte, da jurisdição e do papel do juiz. Os problemas estruturais (externos), ficam aqui em suspenso, eis que dizem respeito as condições de

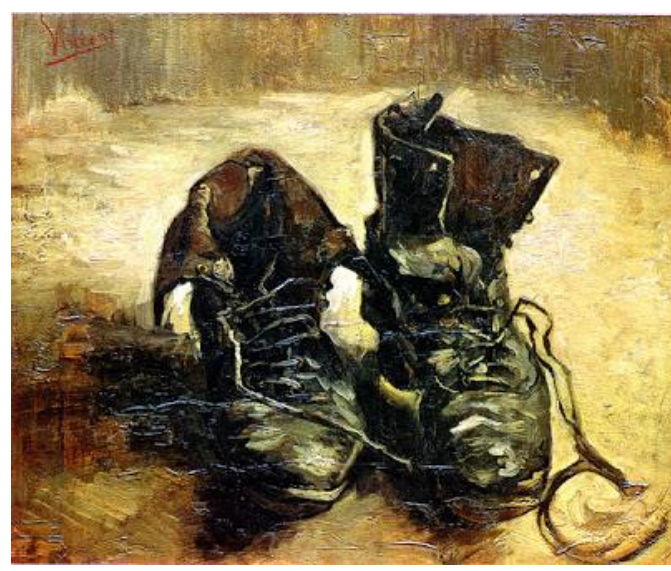

Vincent Van Gogh, O par de botas (1886). possibilidade da jurisdição que se pretenda e não ao momento constitutivo desta (Castanheira Neves, 1998, p. 2). Interessam-nos aqui os problemas internos, os problemas da intencionalidade, do sentido do direito. Pois pensar o sentido da jurisdição é pensar a sua relação com o direito (jurisdictio), consequentemente, um diferente sentido do direito implicará correlativamente um diferente sentido da jurisdição chamada a realizá-lo, ressignificando todo o sistema e, consequentemente estabelecendo, no futuro, novas relações com os problemas jurídicos vindouros ${ }^{23}$. O sistema, portanto, não sai incólume quando provocado por um problema jurídico, integrando uma nova intencionalidade a cada nova provocação. O sentido do direito, e da jurisdição, nasce, sempre de uma práxis (Castanheira Neves, 2002, 2013; Espindola, 2016a). O direito não pode ser reduzido à perspectiva exclusivamente do estrito legalismo. Afirmar isso, por óbvio, não significa abandonar a legalidade! Mas antes: (a) recuperar a autonomia normativo-intencional do direito perante a legalidade, assim como (b) (re)delinear os limites normativo-jurídicos da lei a partir da na realização concreta do direito na jurisdição.

Trata-se, portanto, de defender a autonomia normativo-intencional do direito perante a legalidade (a mera legalidade), nos termos apontados por Castanheira Neves (1998, p. 5), através do reconhecimento da separação dos direitos (especialmente aqueles fundamentais) em relação à lei, bem como do reconhecimento de princípios normativos que transcendam a lei (a legalidade), convocados como fundamentos

\footnotetext{
23 Nesse sentido, ver sobre a tese da refundação da jurisdição em Espindola (2013).
} 
normativos da juridicidade aos quais a própria lei a de submeter-se. Nesta perspectiva, não é a lei que dá validade jurídica aos direitos, mas antes os direitos fundamentais ${ }^{24}$, os quais impõe-se à lei e condicionam a sua validade jurídica (Castanheira Neves, 1998, p. 5-6) 25 .

Quanto aos limites a atuação jurisdicional - necessários para a superação da mera legalidade de modo a proteger a autonomia do direito, obstaculizando o voluntarismo (Castanheira Neves, 1998, p. 8) - é preciso distinguir entre os limites normativos-objetivos e os limites normativosintencionais. Aqueles dizem respeito à dinâmica social, ou seja, ao fato de o direito legalmente positivado estar aquém do domínio históricosocialmente problemático a que se terá de responder jurídiconormativamente. Já os limites normativos-intencionais implicam na superação do sentido lógico-dedutivo e formal, reconhecendo-se a necessidade de mostrar-se concretamente adequada ao mérito problemático dos casos decidendos, vez que o direito que legalmente se realizará é ele próprio um continuum constituendo em função dialética normativa que articula os princípios com o mérito jurídico do problema concreto através da mediação das normas legais (Castanheira Neves, 1998, p. 8-9).

A autonomia normativo-intencional do direito perante a legalidade, balizado por limites normativo-intencionais na realização concreta do direito na jurisdição constituem o sentido axiológico-normativo do direito, de que fala Castanheira Neves (1998, 2002). E é esse sentido axiológiconormativo, resultado constituído pela prática da sua realização históricosocial, que constitui a consciência jurídica geral, nos seus valores, princípios e critérios normativos decisivos. Castanheira (1998, p. 10) evoca, analogicamente, o círculo hermenêutico gadameriano para melhor expor a constituição da consciência jurídica geral e o sentido do direito.

24 O sentido, autêntico e último, destes direitos, segundo Castanheira (1998, p. 5-6), pode ser alcançado por duas perspectivas contrárias: uma delas é a o liberalismo individualista (liberalismo radical), que ainda subsiste e talvez esteja em restauração, e a perspectiva de uma compreensão comunitária, extraída da integração comunitária, segundo a qual os direitos tem deveres como correlatos de sentido. Para Castanheira, o sentido dos direitos fundamentais se dá a partir da antítese entre comunitarismo vs liberalismo, exigindo a superação do indivíduo como titular dos direitos pela de um sujeito que só poderá assumir direitos no contexto de uma cidadania vinculante enquanto pessoa com responsabilidade comunitária.

25 A compreensão de Castanheira Neves neste ponto, que irá culminar no que ele chama de consciência jurídica geral, aproxima-se do círculo hermenêutico gadameriano. 
Nesta perspectiva, o que tem a ver o direito e o intérprete? Se o direito só pode sê-lo enquanto for um transcender axiológico que fundamente e critique as relações humanas na convivência comunitária, se o direito só tem sentido e autonomia como projeto axiológico da vida comunitária, evidentemente não terá lugar numa sociedade que aceite submeter-se ao totalitarismo da redução racional-tecnocrática. Neste ponto reside o papel fundamental do intérprete, que por meio da decisão judicial, não deve reduzir-se a mero técnico dos dispositivos cogentes ou a um burocrata da coação, sob pena de mostrar-se como um anacronismo a ser superado pelo tecnocrata. Ao intérprete (e portanto, à decisão judicial) cumpre o papel de assumir e realizar a ideia de direito, considerando este não como um "dado", um "posto" que o jurista tenha de receber, tampouco que o direito possa estar em algum juízo moral, mas antes trata-se de uma "tarefa" que o concita a um esforço e a uma responsabilidade (Castanheira Neves, 1995b, p. 46-47). Sem isto, temos a fratura entre o direito e o homem.

Agregue-se a isto o fato de a postulação de direitos dar-se por meio de uma complexa polifonia narrativa ${ }^{26}$ de versões, como refere Calvo Gonzáles (1998; 2008). De modo que, na atuação jurisdicional há um amplo espectro narrativo de intrincadas versões e inversões sobre/dos fatos. O intérprete, tal como o neurologista na metáfora do conto de Sacks, também é um narrador que trará a sua versão sobre os fatos, que deverá intervir mínima e excepcionalmente, com vistas a realizar um verdadeiro ajuste de contas (dar conta, dar fundamento), para novamente citar Calvo Gonzáles (1998, p. 12-14). Esse ajuste de contas, por certo, transforma a verdade judicial em uma verdade histórica, a verdade dos fatos contados, ou seja, é aquilo que se julga ter acontecido, porém, dentro de uma coerência narrativa, a partir da construção de uma ratio decidenti como relato justificatório suficiente e razoável(Calvo González, 1998, p. 7-38). Sem isso não há como saber se o homem confundiu a mulher com um chapéu, ou se ele exatamente não a confundiu por puro acaso.

Este, portanto, o tratamento terapêutico para o diagnóstico do legalismo ou do voluntarismo, identificados ambos como lesões gravíssimas

26 Sobre o tema "polifonia e verdades nas narrativas processuais" recomenda-se, em especial, Trindade e Karam (2018). 
aos hemisférios esquerdo ou direito do cérebro da Constituição trintagenária e, portanto, responsáveis pelos défices interpretativos.

\section{CONSIDERAÇÕES FINAIS}

Mulheres não são chapéus, embora chapéus possam estar em cabeças femininas. Ceci n'est pas une pipe, embora a imagem possa representar um cachimbo, ou uma forma histórica, comunitária e cultural de vê-lo. O direito não é o que os tribunais dizem, embora tribunais possam dizer o direito - juris dictio. Assim como Sacks espanta-se diante de seu paciente que confunde a mulher com um chapéu, o pé com o sapato, crianças com hidrantes e parquímetros, maçanetas com rostos, é espantoso como mesmo após a viragem proporcionada pela filosofia hermenêutica e pela hermenêutica filosófica para a interpretação do direito ${ }^{27}$, ainda possamos confundir o direito com a moral ou reduzi-lo àquilo que os tribunais ditam.

De fato, estas "confusões" sugerem que o locus privilegiado da relação sujeito-objeto (o positivismo) ainda subsiste, tendo por consequência o agigantamento do solipsismo subjetivista em detrimento de um contexto intersubjetivo de fundamentação (Streck, 2011). Tudo isso somado à constatação de Picardi (2008, p. 1-32) de que estamos num século vocacionado para o judiciário, culmina inevitavelmente para o ativismo judicial ${ }^{28}$. O judiciário, apesar da enorme (e incontornável) responsabilidade política inerente à prestação jurisdicional, comporta-se tal qual o carro de jagrená $^{29}$, perdendo o domínio sobre as circunstâncias e tornando-se vítima de suas próprias obras. No constitucionalismo contemporâneo brasileiro já estivemos mais próximos desta ruptura paradigmática.

O papel do intérprete é descobrir a pergunta a qual o texto (sistema e problema) vem dar a resposta. Por isso que compreender um texto é, antes, compreender a pergunta. De fato, se afirmamos, com Gadamer (1997, p.

27 Para uma compreensão das simetrias e assimetrias entre o jurisprudencialismo de Castanheira Neves e a crítica hermenêutica do direito de Lenio Streck, tema aqui não explorado, consultar Streck (2011, p. 163-168).

28 Para uma distinção entre judicialização da política e ativismo judicial, bem como para uma compreensão alargada sobre como o ativismo judicial fragiliza a autonomia do direito, ver Streck (2012), Tassinari (2013), Trindade e Morais (2011), Trindade e Rosenfield (2015).

29 Carro de Jagrená é uma metáfora utilizada por Giddens (1991). Jagrená é uma divindade hindu que, em cultos místicos, conduz um carro de trajetória errante sob cujas rodas os devotos se expõem a ser atropelados (Giddens, 1991). 
565-568), que todo compreender é interpretar, e todo interpretar se desenvolve no medium de uma linguagem que pretende deixar falar o objeto e é, ao mesmo tempo, a linguagem própria de seu intérprete, compreendemos também o direito como um constituto constituendo (Castanheira Neves, 2013), assim como também aceitamos que a busca por respostas adequadas, como afirma Streck (2017, p. 386), é um remédio contra o cerne do modelo que dialeticamente, o engendrou: o positivismo e sua característica mais forte, o voluntarismo, a arbitrariedade.

\section{REFERÊNCIAS}

BARROSO, L. R. Judicialização, ativismo judicial e legitimidade democrática. Anuário Iberoamericano de Justiça Constitucional, v. 13, n. 1, p. 17-32, 2009.

CALVO GONZÁLEZ, J. Verdad, [narración], justicia. Andalucía: Servicio de Publicaciones e Intercambio Científico de la Universidad de Málaga, 1998.

CALVO GONZÁLEZ, J. Implicación, derecho, literatura: contribuciones a una teoría literaria del derecho. [s.l: s.n.].

CÁRCOVA, C. M.; PRICE, J. E. D.; RUIZ, A. E. C. Estudios sobre el derecho y la literatura. Buenos Aires: Infojus, 2014.

CASTANHEIRA NEVES, A. Digesta: escritos acerca do direito, do pensamento jurídico e da sua metodologia e outros, 2. Coimbra: Coimbra Editora, 1995a.

CASTANHEIRA NEVES, A. Digesta: escritos acerca do direito, do pensamento jurídico e da sua metodologia e outros, 1. Coimbra: Coimbra Editora, 1995b.

CASTANHEIRA NEVES, A. Entre o legislador, a sociedade e o juiz ou entre sistema função e problema - Os modelos actualmente alternativos da realizacao jurisdicional do direito. Boletim da Faculdade de Direito da Universidade de Coimbra, v. 74, p. 1-44, 1998.

CASTANHEIRA NEVES, A. O direito hoje e com que sentido? O problema actual da autonomia do direito. Lisboa: Instituto Piaget, 2002.

CASTANHEIRA NEVES, A. O actual problema metodológico da interpretação jurídica, I. Coimbra: Coimbra Editora, 2003.

CASTANHEIRA NEVES, A. Metodologia jurídica: problemas fundamentais. Coimbra: Coimbra Editora, 2013.

CHUEIRI, V. K. de. Direito e literatura. In: BARRETO, V. de P. (Coord.). Dicionário de filosofia do direito. Rio de Janeiro: Renovar, 2006.

CITTADINO, G. Poder judiciário, ativismo judicial e democracia. Revista da Faculdade de Direito de Campos, v. 2-3, n. 2-3, p. 135-144, 2001. 
COVER, Robert. Nomos e narração. Anamorphosis - Revista Internacional de Direito e Literatura, Porto Alegre, RDL, v. 2, n. 2, p. 187-268, jul.-dez. 2016. doi: 10.21119/anamps.22.187-268.

DORETTO, D. Fisiopatologia clínica do sistema nervoso: fundamentos da semiologia. 2. ed. Rio de Janeiro: Atheneu, 2002.

DWORKIN, R.; RIOS, G. O império do direito. São Paulo: Martins Fontes, 1999.

ESPINDOLA, A. A. da S. A refundação da jurisdição e a concretização dos direitos fundamentais. Revista Eletrônica Direito e Política, v. 8, n. 3, 2013. doi: 10.14210/rdp.v8n3.p2101-2125.

ESPINDOLA, A. A. da S. Entre a insustentabilidade e a futilidade: a jurisdição, o direito e o imaginário do juiz. In: STRECK, L. L.; TRINDADE, A. K. (Org.). Os modelos de juiz: ensaios de direito e literatura. São Paulo: Atlas, 2015. p. 19-44.

ESPINDOLA, A. A. da S. O jurisprudencialismo e o garantismo processual como alternativas para a crise da jurisdição brasileira. Revista do Mestrado em Direito da Universidade Católica de Brasília (RVMD), v. 10, n. 2, p. 355-377, 2016a. doi: 10.18840/rvmd.v10i2\%20Jul/Dez.7659.

ESPÍNDOLA, Angela Araújo da Silveira. Entre a insustentabilidade e a futilidade: a jurisdição, o direito e o imaginário social sobre o juiz = Between unbearableness and futility: jurisdiction, law, and the social imaginary about the judge. Anamorphosis - Revista Internacional de Direito e Literatura, Porto Alegre, RDL, v. 2, n. 2, p. 293-320, jul.-dez. 2016b. doi: 10.21119/anamps.22.293-320.

GADAMER, H.-G. Verdade e método: traços fundamentais de uma hermenêutica filosófica. 5. ed. Petrópolis (RJ): Vozes, 1997. v. 1.

GIDDENS, A. As consequências da modernidade. São Paulo: Unesp, 1991.

HOBSBAWM, E. Era dos extremos: o breve século XX. São Paulo: Companhia das Letras, 1995 .

HOBSBAWM, E. Tempos interessantes. São Paulo: Companhia das Letras, 2002.

KARAM, H. O direito na contramão da literatura: a criação no paradigma contemporâneo. Revista Eletrônica do Curso de Direito da UFSM, v. 12, n. 3, p. 1022-1043, 2017. doi: 10.5902/1981369429566.

KARAM, H.; ALCÂNTARA, G. G. História, direito e literatura: uma triangulação em prol do Constitucionalismo. Revista Opinião Jurídica, Fortaleza, v. 17, n. 24, p. 204-223, 30 nov. 2019. doi: 10.12662/244766410j.v17i24.p204-223.2019.

MARSHALL, P. Awakenings (Tempo de despertar). Estados Unidos da América.LK-Tel Vídeo, LK-Tel Vídeo, Columbia Pictures, Sony Pictures, , 1990.

NUSSBAUM, M. Justicia poetica. Barcelona: Editorial Andres Bello, 1997.

OLIVO, L. C. C. DE. O estudo do direito através da literatura. Tubarão: Studium, 2013.

PICARDI, N. Jurisdição e processo. Rio de Janeiro: Forense, 2008. 
RORTY, R. El giro lingüístico. Barcelona: Paidós, 1990.

SACKS, O. O homem que confundiu sua mulher com um chapéu. São Paulo: Companhia das Letras, 1997.

SCHOPENHAUER, A. O mundo como vontade e representação. [s.l: s.n.].

SCHWARTZ, G.; MACEDO, E. Pode o Direito ser arte? Respostas a partir do direito \& literatura. In: XV Congresso Nacional de Pesquisa e PósGraduação em Direito-CONPEDI, 2006, Manaus. Anais... [s.l: s.n.]. p. 1013-1031.

SEGRE, C. Narração/narratividade, 1989. (Nota técnica).

STEIN, E. Gadamer e a consumação da hermenêutica. In: STEIN, E.; STRECK, L. L. (Org.). Hermenêutica e epistemologia: 50 anos de verdade e método. Porto Alegre: Livraria do Advogado, 2011. p. 9-24.

STRECK, L. L. Hermenêutica jurídica e $(m)$ crise. Porto Alegre: Livraria do Advogado, 1999.

STRECK, L. L. Hermenêutica, constituição e autonomia do Direito. Revista de Estudos Constitucionais, Hermenêutica e Teoria do Direito, v. 1, n. 1, p. 65-77, 2009a.

STRECK, L. L. O problema da decisão jurídica em tempos pós-positivistas. Novos Estudos Jurídicos, v. 14, n. 2, p. 3-26, 2009 b.

STRECK, L. L. Hermenêutica e decisão judicial: questões epistemológicas. In: STEIN, E.; STRECK, L. L. (Org.). Hermenêutica e epistemologia: 50 anos de verdade e método. Porto Alegre: Livraria do Advogado, 2011. p. 153-172.

STRECK, L. L. O que é isto - Decido conforme minha consciência? 3. ed. Porto Alegre: Livraria do Advogado, 2012.

STRECK, L. L. Verdade e consenso: constituição, hermenêutica e teorias discursivas: da possibilidade à necessidade de respostas corretas em direito. 6. ed. São Paulo: Saraiva, 2017.

STRECK, L. L. Fatos, relatos e interpretações. In: TRINDADE, A. K.; KARAM, H. (Ed.). Por dentro da lei: direito, narrativa e ficção. Florianópolis: Tirant Lo Blanch, 2018a. p. 81-98.

STRECK, L. L. Enunciados assertóricos no Direito brasileiro: a busca por respostas antes das perguntas vista a partir da literatura e da crítica hermenêutica do Direito. Revista Brasileira de Direito Processual: RBDPro, v. 26, n. 101, p. 213-228, 2018 b.

STRECK, L. L. Erro judiciário. Programa Direito e Literatura. TV Justiça., 2018c.

STRECK, L. L. E a senhora Constituição, 30 anos, foi confundida com um chapéu? Conjur. Consultor Jurídico, 4 out. 2018d.

STRECK, L. L.; TRINDADE, A. K. Direito e literatura: da realidade da ficção à ficção da realidade. São Paulo: Atlas, 2013.

TASSINARI, C. Jurisdição e ativismo: limites de atuação do judiciário. Porto Alegre: Livraria do Advogado, 2013. 
TRINDADE, A. K. Kafka e os paradoxos do direito: da ficção à realidade. Revista Diálogos do Direito, v. 2, n. 51, p. 137-159, 2012. doi: 10.17793/rdd.v2i2.63.

TRINDADE, André Karam; BERNSTS, Luísa Giuliani. O estudo do direito e literatura no Brasil: surgimento, evolução e expansão = The study of "law and literature" in Brazil: development, evolution and expansion . Anamorphosis - Revista Internacional de Direito e Literatura, Porto Alegre, RDL, v. 3, n. 1, p. 225-257, jan.-jun. 2017. doi: 10.21119/anamps.31.225-257.

TRINDADE, A. K.; KARAM, H. Polifonia e verdade nas narrativas processuais. Sequência, Florianópolis, n. 80, p. 51-74, 2018. doi: 10.5007/2177-7055.2018v39n8op51.

TRINDADE, A. K.; MORAIS, F. S. DE. Ativismo Judicial: as experiências norte-americana, alemã e brasileira. Revista da Faculdade de Direito $U F P R$, v. 53, p. 137-164, 2011. doi: 10.5380/rfdufpr.v53io.30764.

TRINDADE, A. K.; NETO, J. C. D. Os (des)acertos do legislador na "positivação" das teorias de Robert Alexy no direito processual civil brasileiro. Revista Eletrônica do Curso de Direito da UFSM, v. 12, n. 3, p. 1044-1067, 2017. doi: 10.5902/1981369429603.

TRINDADE, A. K.; ROSENFIELD, L. Réquiem para Ivan Ilitch: o problema da interpretação do direito na literatura de Tolstói. Revista da Faculdade de Direito - UFPR, v. 60, n. 2, p. 157-176, 2015. doi: 10.5380/rfdufpr.v60i2.39181.

VESPAZIANI, Alberto. Il potere del linguaggio e le narrative processuali $=$ $\mathrm{O}$ poder da linguagem e as narrativas processuais. Anamorphosis - Revista Internacional de Direito e Literatura, Porto Alegre, RDL, v. 1, n. 1, p. 69-84, jan.-jun. 2015. doi: 10.21119/anamps.11.69-84. 